\title{
Aspectos da dinâmica da família com dependência química
}

\author{
Fernanda Marques Paz \\ Psicóloga \\ Patrícia Manozzo Colossi \\ Faculdades Integradas de Taquara
}

\begin{abstract}
Resumo
O envolvimento da família no tratamento tem sido apontado como preditor de sucesso terapêutico da dependência química. Nesse sentido, foi realizada uma investigação qualitativa, utilizando o estudo de caso de dependente químico e sua família, atendidos por instituição de saúde, para identificação da dinâmica relacional estabelecida nestes contextos. Para a coleta de dados foram utilizados entrevistas, genograma e registros de grupos de familiares. A análise dos dados se deu a partir da compreensão sistêmica da família. $\mathrm{O}$ estudo realizado aponta a necessidade de compreensão da dependência química como fenômeno que pode ser influenciado pela dinâmica familiar reforçando aspectos de seu funcionamento para a manutenção do sintoma. Tratar a disfuncionalidade familiar pode constituir-se um fator de proteção ao uso de drogas e prevenção à recaída.
\end{abstract}

Palavras-chave: dependência de substâncias psicoativas; relações familiares; teoria familiar sistêmica.

\begin{abstract}
Chemical dependence family dynamic aspects. The involvement of family in treatment has been pointed like the predictor of chemical dependence therapeutic success. In this sense, a quality investigation was done, using the case study of addict and his family, assisted by a health institution, selected by convenience, for the identification of familial relations manifestation in these contexts. For the data collecting, interviews, genogram and family groups records were used. The data analysis was done from the family systemic comprehension. The study points out the need of understanding chemical dependency as a phenomenon that can be influenced by familiar dynamic, reinforcing functioning aspects to the symptom maintenance. Treating the familiar disfunctioning is a protection factor to the drugs using, and prevention to relapse.
\end{abstract}

Keywords: chemical dependence; family relationships; family systems theory.

\section{Resumen}

Aspectos de la dinámica de la familia con dependencia química. El envolvimiento de la familia en el tratamiento ha sido factor indispensable del suceso terapéutico de la dependencia química. En ese sentido, fue realizada una investigación cualitativa, utilizando el estudio sobre el dependiente químico y su familia, atendidos por Instituición de la Salud, para identificación de la dinámica relacional establecida en estos contextos. Para la colecta de datos fueron utilizados encuestas, genograma y registros de grupos familiares. Los análisis de los datos ocurrieron a partir de la comprensión sistémica de la familia. El estudio realizado apunta la necesidad de comprensión de la dependencia química como fenómeno que puede ser influenciado por la dinámica familiar, reforzando aspectos de su funcionamiento para la manutención de sintoma. Tratar la disfuncionalidad familiar puede constituirse un factor de protección al uso de drogas y prevención a la recaída.

Palabras clave: dependencia de sustancias psicoativas; relaciones familiares; teoria familiar sistémica.

\section{Histórico do tratamento em dependência química}

Pesquisas na área de dependência química têm revelado a importância da família como fator de proteção e prevenção à recaída (Carvalho \& Almeida, 2003; De Micheli \& Formigoni, 2001; Fliglie, Fontes, Moraes, \& Payà, 2004). Nos últimos anos, a adição e suas consequências na vida do indivíduo e sua família têm sido consideradas um problema de saúde pública, sendo um fenômeno de grande relevância social e acadêmica, já que seu tratamento implica na articulação de múltiplas abordagens terapêuticas (Silva, 2001).

Entre as modalidades de tratamento adotadas nestes casos, as mais comumente utilizadas são as internações em comunidades 
terapêuticas (CT) ou clínicas de desintoxicação, os atendimentos nos centros de atenção psicossocial para álcool e outras drogas (Caps Ad) e a participação de grupos de apoio, também chamados de grupos de auto-ajuda.

As CTs são modalidades de atenção à saúde surgidas na Grã-Bretanha na década de 1940, utilizadas para tratamento de pacientes psiquiátricos crônicos e posteriormente adaptadas à terapêutica de dependentes químicos (Raupp \& MulnitiskySapiro, 2008). Constituem-se em espaços de tratamento de longo prazo para psicodependentes, administrados por exusuários de drogas previamente internados nessas instituições. Os residentes, assim chamados os pacientes internados na $\mathrm{CT}$, precisam permanecer um período de nove meses sem qualquer recaída para obterem alta e a graduação. A partir de então, podem permanecer na instituição, trabalhando como monitores, se assim desejarem (De Leon, 2003).

Já as clínicas de desintoxicação podem ser centros de tratamento específico, destinado a pacientes adictos, como também leitos demarcados em hospitais gerais públicos ou privados, consistindo uma forma relativamente segura, que visa monitorar sintomas de abstinência, controlando complicações físicas e psicológicas (Zeni \& Araújo, 2011). Para Laranjeira e Romano (2004) a desintoxicação é a primeira fase do tratamento, associada a altos índices de recaída. Nesta modalidade terapêutica, os índices de abstinência após a alta é relativamente maior quando o paciente é acompanhado por cuidados ambulatoriais posteriores, inserido em programas de acompanhamento psicológico.

Os CAPS Ad constituem-se em unidades locais de saúde pública regionalizadas que oferecem atendimento especializado a usuários de álcool e outras drogas, criados em substituição aos hospitais psiquiátricos e seus métodos de tratamento do sofrimento mental (Brasil, 2003).

Como opção terapêutica destacam-se, ainda, os grupos de auto-ajuda, coordenados por ex-usuários ou algum familiar envolvido com uso/abuso/dependência de drogas. Destacam-se os AAs (Alcoólicos Anônimos) e os NAs (Narcóticos Anônimos), reconhecidos e atuantes nos cinco continentes desde 1935, tendo sua origem nos Estados Unidos e posteriormente, difundido ao redor do mundo (Alcóolicos Anônimos, 2011).

As possibilidades terapêuticas até aqui referidas são opções de tratamento que pouco contemplam a inserção familiar. Entretanto, a literatura existente acerca da temática tem referido a importância do enfoque familiar para o tratamento das adições (Schenker \& Minayo, 2003). Schenker e Minayo (2004) reforçam as ideias já apontadas por Sudbrack (2001) ressaltando a importância da inclusão da família no tratamento, oportunizando a modificação dos padrões familiares, contribuindo assim, para uma dinâmica familiar funcional. De acordo com Payà (2011) a família com dependência química pode ser considerada uma rede de inter-relações na qual seus valores, crenças, emoções e comportamentos, influenciam os membros da família e são, por ela, influenciados.

Nesse sentido, Fliglie, Bordin e Laranjeira (2010) apontam a terapia familiar como modalidade terapêutica que contribui para a mudança do comportamento abusivo e qualidade de vida familiar. Com isso, do ponto de vista sistêmico, a drogadição pode ser entendida como sintoma da família, em que o doente não é apenas o paciente identificado, mas todo o sistema familiar. Assim, a família busca ajuda para o familiar adicto sem, contudo, modificar suas relações. Com isso, o sujeito sintomático parece ficar refém de uma família que resiste a mudanças (Andolfi, Ângelo, Menghi, \& Nicolo-Corigliano, 1984; Minuchin \& Fishman, 1990).

Diferentes autores (Moreira, 2004; Seadi \& Oliveira, 2009) reforçam a mesma ideia referindo que o sintoma da adição está a serviço da manutenção da homeostase familiar, encobrindo conflitos arraigados à estrutura familiar. Assim, a melhora do dependente químico pode revelar conflitos que a família não sabe como lidar, desequilibrando o sistema. Deste modo, os benefícios da terapia familiar sistêmica nesses contextos são associados à reorganização do sistema familiar, estabelecendo assim, a possibilidade de novos arranjos familiares bem como a melhora dos padrões de comunicação, dos limites e das fronteiras entre os subsistemas (Payà, 2011).

\section{Dependência química e funcionamento familiar}

A dinâmica familiar pode ser compreendida, segundo Minuchin e Fishman (1990), considerando a estrutura, os subsistemas e as fronteiras do funcionamento da família. A estrutura familiar pode ser definida como "um conjunto invisível de exigências funcionais que organiza as maneiras pelas quais os membros da família interagem" (Minuchin, 1982, p. 57). Ela não é facilmente percebida, sendo expressa através dos subsistemas, da hierarquia, dos papeis e das fronteiras, dentre outras dimensões do funcionamento familiar.

Já os subsistemas são "agrupamentos familiares baseados em gerações, gêneros e interesses comuns" (Nichols \& Schwartz, 2007 , p. 184). Assim, cada indivíduo pode pertencer a diferentes subsistemas, desenvolvendo papéis diferentes em cada um deles (Nichols \& Schwartz, 2007) e embora alguns subsistemas sejam comuns, as possibilidades de agrupamentos em subsistemas são infinitas.

Nichols e Schwartz (2007) referem que os indivíduos, os subsistemas e as famílias são demarcados por fronteiras, nas quais as "barreiras invisíveis que envolvem os sujeitos e os subsistemas e regulam o contato com os outros" (p.184). A nitidez das fronteiras apresenta-se como um parâmetro importante para a avaliação do funcionamento familiar, revelando maior ou menor funcionalidade da família. Minuchin e Fishman (1990) referem que o estabelecimento de fronteiras pode indicar possíveis patologias já que tanto fronteiras excessivamente rígidas quanto difusas denotam, em algum nível, um padrão disfuncional de funcionamento familiar. Minuchin e Fishman (1990) definem as fronteiras rígidas como restritivas, já que permitem pouco contato com subsistemas externos, resultando em relações distanciadas. Por vezes, não garantem o apoio mútuo intra-familiar, expressando um sentido distorcido de independência, já que o estresse de um familiar parece afetar os outros apenas quando em um nível muito elevado. Em contrapartida, as fronteiras difusas revelam famílias emaranhadas, já que seus subsistemas desenvolvem um sentimento de apoio mútuo às custas da autonomia de seus membros. Com fronteiras enfraquecidas, levam comumente 
seus membros a reagirem exageradamente e de forma intrusiva uns com os outros (Nichols \& Schwartz, 2007). Exemplo deste tipo de famílias é a com dependentes químicos, que costumam apresentar limites geracionais frágeis e o conflito no exercício dos papéis familiares (Moreira, 2004), sendo comum o filho adolescente estar triangulado no conflito parental, apresentando, por vezes, segredos e mentiras, que funcionam como mecanismos de proteção e negação do comportamento dependente (Penso \& Sudbrack, 2004).

As famílias com filhos adolescentes experimentam uma transformação dos vínculos infantis de relacionamento, por um tipo de vínculo mais maduro e independente. Estudos mostram (Brasil, 2004; Kalina, 1999; Melo, Caldas, Carvalho, \& Lima, 2005; Penso, 2003; Sudbrack, 2001) que a fase do ciclo vital que, comumente, se inicia o uso de substâncias psicoativas é aquela em que os filhos passam pela adolescência, já que buscam maior autonomia e independência ao mesmo tempo em que começam a se desligar, progressivamente, da família de origem. Penso (2003) aponta o uso de substâncias como parte do processo de aquisição de autonomia do adolescente em relação ao sistema familiar, relacionado ao processo de separaçãoindividuação. A perspectiva sistêmica considera a dimensão relacional do processo de individuação, a partir do modo como pais e adolescentes lidam com este processo no ciclo vital da família (Guimarães, Costa, Pessina, \& Sudbrack, 2009). Assim, a individuação do adolescente pode ser vivida pela família com grande sofrimento, estando relacionado com a dificuldade em aceitar as mudanças (Guimarães, Costa, \& Lima, 2002). Com isso, os sintomas de comportamento surgem já que a estrutura familiar não consegue se adaptar a determinadas situações estressoras. A dificuldade de adaptação às referidas situações pode desencadear o que Achenbach e Howell (1993) definem como sintomas internalizantes, quando expressos em relação ao próprio indivíduo (tristeza, angústia, queixas somáticas, medo, depressão, ansiedade, etc); ou externalizantes, quando manifestos na conduta e em relação a outras pessoas (hiperatividade, agressividade, dificuldade no controle de impulsos, raiva, delinquência, uso/abuso/dependência de drogas, etc.).

Conforme Gerson e McGoldrick (2001), esses estressores podem ser desenvolvimentais, sendo esperados nas transições no ciclo de vida da família ou impredizíveis, acontecendo abruptamente na história da família. Nesse sentido, as mesmas autoras referem que a crise familiar advém da combinação de forte estresse e fracasso no realinhamento dos papéis e funções frente às novas exigências. Assim, os fatores estressores parecem demasiadamente intensos e impactam a família em sua capacidade de adaptação, provocando o aparecimento de sintoma. A coesão familiar pode ser identificada a partir da codependência, em que os laços afetivos parecem indestrutíveis e estáveis. As mudanças no ciclo de vida familiar, assim como os estressores, deveriam, via de regra, modificar estes vínculos, mas, ao contrário, eles permanecem inalterados, mantendo a homeostase do sistema familiar (Beatite, 2007).

Estudos apontam a importância familiar na drogadição (Carvalho, 2001; De Micheli, Fisberg, \& Formigoni, 2004), já que os fatores familiares têm sido relacionados ao uso, abuso e/ou dependência de drogas, comprometendo a coesão e o funcionamento familiar. Copello, Velleman e Tempelton (2005) tentam detectar associações do tipo causa-efeito que expliquem a gênese do uso de drogas dos filhos. Aspectos preditores do abuso de substâncias destacam-se como: alcoolismo de um dos pais, transmissão genética familiar, separação dos pais, estrutura e relação afetiva familiar, dificuldade de comunicação com os pais na adolescência (Rodrigues, Horta, Costa, Macedo, \& Strey, 2008). Ainda que essas condições possam ser consideradas, parecem tentativas lineares de compreensão do fenômeno da dependência química. Situações familiares de maior risco e vulnerabilidade para a dependência química são apontadas por Horta, Horta e Pinheiro (2006) como os contextos de violência intra-familiar e/ou o uso de substâncias psicoativas por um dos progenitores. Cecconello e Koller (2003) descrevem as famílias que suportam fortes pressões socioeconômicas e as de padrões educacionais rígidos e punitivos com os filhos. Nunõ-Guitièrrez e Gonzalez-Fortaleza (2004) apontam a comunicação conflituosa e triangulada, a presença de conflitos conjugais, geracionais ou a existência de alianças intergeracionais, os contextos de violência intra-familiar e, ainda, os modelos repetitivos de perpetuação do uso de drogas em um ambiente familiar desfavorável ao afeto como aspectos que podem predizer o uso de substâncias nos filhos.

Considerando aspectos terapêuticos, Landau (2004) refere a importância da família e rede social como fatores de motivação ao tratamento e à recuperação. Desta forma, a drogadição é concebida como sintoma, como forma de comunicação ou expressão da crise (Guimarães et al., 2009). Osório e Valle (2009) referem o uso de drogas como uma incapacidade de entrar em contato com crises individuais e/ou sociais, numa tentativa de resolução de processos existenciais frente às angústias e características da modernidade.

Famílias que produzem dependentes químicos são definidas por Kalina (2001) como “famílias psicotóxicas”, já que a busca de substâncias psicoativas para o enfrentamento dos problemas se apresenta como modelo indutor abusivo, representando, não raro, a dupla mensagem parental, já que o discurso refere à proibição e o comportamento não verbal é o do uso de substâncias para alívio do sofrimento (tranquilizantes, álcool, etc).

Quando o paciente inicia o tratamento para a dependência química, a droga perde o lugar privilegiado da atenção familiar e o paciente começa a reinvestir, progressivamente, em contextos de vida mais saudáveis. Com isso, a família rompe a homeostase até então estabelecida e o casal precisa mudar seu foco de atenção, permitindo a melhora do filho. O filho usuário de drogas sai do lugar de investimento parental fazendo com que o casal se depare com a própria relação conjugal. Assim, os conflitos antes deixados de lado, pela preocupação com o filho, tendem a reaparecer, colocando em risco o relacionamento conjugal dos pais. A fim de proteger o casal parental, o filho volta a comportar-se de maneira autodestrutiva, chamando, novamente, a atenção da família. Com isso, promove a união do casal em torno de si, mobilizados pela sintomatologia adicta, contribuindo para a manutenção da homeostase do sistema familiar. Neste caso, o sintoma da drogadição funciona como estabilizador do sistema familiar, pois, se o problema da adição perdura, o conflito conjugal permanece às escondidas. Assim, cabe dizer 
que o conflito parental constitui-se num aspecto preditor da manutenção da sintomatologia adicta, piorando os sintomas do filho (Orth, 2005).

Nesse sentido, compreender a dinâmica da família do dependente químico possibilita não apenas o entendimento que o sintoma exerce sobre seus membros, como pode ser capaz de apontar posteriores possibilidades de intervenção. Após a identificação da dinâmica familiar predominante na dependência química, pode-se pensar em recuperação, não apenas do indivíduo usuário/abusador/dependente químico, mas do sistema familiar em que está inserido. Assim, ao ampliar a compreensão do fenômeno da dependência química para o dependente químico e seu contexto familiar, identificando aspectos que favorecem e perpetuam a sintomatologia, parece-nos possível construir novas possibilidades de intervenção, de modo a minimizar o sofrimento e restaurar relações afetivas e individualidades prejudicadas pelo contexto de uso e/ou abuso de substâncias. A intervenção na família torna possível a transformação do contexto do qual o paciente dependente químico faz parte, tocando e sendo tocado por ele.

Considerando o exposto, investigar os aspectos da dinâmica familiar presentes nos contextos de dependência química torna-se relevante no que tange às possibilidades de intervenções mais adequadas à problemática, justificando, de modo significativo, a realização deste estudo.

\section{Método}

Com o intuito de realizar um estudo de caso exploratório, foi escolhido um caso clínico atendido em um serviço público de saúde mental em cidade do interior de estado do Rio Grande do Sul. O caso foi atendido individualmente em um Centro de Atenção Psicossocial- Álcool e Drogas (CAPS - Ad)- e teve como critério de inclusão a frequência do paciente dependente químico no atendimento psicológico individual e a participação de algum familiar no Grupo de Orientação Familiar de Dependentes Químicos sendo, com isso, escolhido por conveniência. O caso foi acolhido pelo serviço através de triagem e encaminhado para atendimento individual. De modo simultâneo, seus familiares foram encaminhados ao grupo de apoio aos familiares de dependentes químicos. Contudo, após cinco atendimentos individuais, a partir da relevância para a evolução do caso, a família foi convidada a integrar o atendimento psicoterápico.

Foi realizada uma entrevista com o paciente e sua mãe, ocasião em que foram convidados a participar do presente estudo. Foram apresentados e discutidos os Termos de Consentimento Livre e Esclarecido (TCLE) e, mediante o aceite e assinatura dos participantes, deu-se o início da coleta de dados. Foram utilizados entrevistas psicológicas, genograma familiar e os relatos do grupo de orientação familiar de dependentes químicos como instrumentos de coleta de dados. E em atenção aos critérios da Resolução 196/96 do Conselho Nacional de Saúde e CFP 016/2000, a presente pesquisa foi avaliada e aprovada pelo Comitê de Ética da Universidade do Vale do Rio dos Sinos (UNISINOS). Os dados coletados foram registrados em arquivo computadorizado e posteriormente foram analisados segundo a teoria sistêmica da família, a partir de uma compreensão dinâmica do caso, e os resultados são descritos neste artigo. Foram categorias de análise: os aspectos constitutivos da dinâmica familiar, os aspectos transgeracionais e experiências de uso/abuso/dependência de álcool e drogas na família de origem. As entrevistas foram realizadas no CAPS da cidade, local que conta com os seguintes atendimentos: clínica médica, clínica psiquiátrica, psicoterapia individual, psicoterapia de grupo, grupo de apoio aos familiares de dependentes químicos e laborterapia com pacientes adictos e pacientes em geral.

\section{Instrumentos}

Entrevistas psicológicas. Registros dos atendimentos psicoterápicos com periodicidade semanal, realizados na instituição de saúde com o paciente individual. Os registros foram feitos no formato de entrevistas dialogadas, registradas em arquivo computadorizado durante cinco meses de atendimento, totalizando 20 entrevistas. Durante este período, Eduardo ${ }^{1}$ compareceu individualmente por cinco sessões. Após este período, a família foi convidada a integrar o tratamento dando continuidade a sessões de terapia familiar. As duas sessões seguintes aconteceram com a presença de Eduardo e seus pais. A partir da segunda sessão familiar, o pai de Eduardo desistiu da terapia, revelando dificuldade de compreender o sintoma da dependência química como pertencente ao núcleo familiar e não apenas ao filho, depositário do sintoma. A partir desse momento, as sessões seguintes aconteceram com Eduardo e a mãe, semanalmente, em atendimentos sucessivos e com uma hora de duração.

Genograma. Representa o mapeamento gráfico da "história e padrão familiar mostrando os relacionamentos da família" (Gerson \& McGoldrick, 2001, p. 145) explorando, ainda, esquemas familiares, revelando a estrutura através das gerações e eventos marcantes do ciclo de vida familiar. Segundo Crepaldi e Wendt (2008), as informações que ele reúne podem incluir aspectos genéticos, médicos, sociais, comportamentais, relacionais e culturais, que denotam a estrutura e configuração da família dando indícios de seu funcionamento e dinâmica, além de possibilitar a compreensão dos relacionamentos e dos padrões transgeracionais. As mesmas autoras propõem ainda que o genograma tem sido difundido como um instrumento científico para coleta de dados, especificamente em pesquisas qualitativas com foco na família (2008). O genograma familiar foi realizado na quarta sessão, em que Eduardo compareceu acompanhado de sua mãe.

Descrição das sessões de grupo de orientação familiar de dependentes químico. O Grupo de Orientação Familiar tem periodicidade semanal, com duração de uma hora e meia. É um grupo aberto, com participantes conforme demanda. As temáticas abordadas possuem relação direta com contexto familiar, uso/ abuso de substâncias e representação acerca do sintoma. As descrições das sessões do grupo referem-se à participação da mãe do paciente dependente químico durante 20 semanas, período em que permaneceram em atendimento psicológico simultâneo, e contemplam apenas a participação da mãe do paciente identificado, já que o pai, embora convidado a participar, não compareceu a nenhum encontro de grupo. Os relatos foram igualmente registrados a partir da transcrição das sessões em 
arquivo computadorizado.

\section{Resultados}

\section{Descrição e discussão do caso}

Carla, mãe de Eduardo (estudante universitário, 20 anos), buscou o serviço de saúde mental há cerca de oito meses, à procura de atendimento psicológico para o filho, então, usuário de cocaína. Foi marcada uma primeira consulta, a partir da qual seguiram-se atendimentos individuais semanais durante as primeiras cinco semanas, passando a atendimentos familiares nas 16 semanas seguintes, além de acompanhamento médico mensal para administração de medicação psiquiátrica, durante o mesmo período. A frequência e pontualidade de Eduardo às consultas foram inconstantes, expressando uma característica de seu comportamento com quase todas as coisas que o envolve. Em diferentes contextos de sua vida, revela baixo nível de comprometimento e valorização daquilo que realiza. Eduardo revelava dificuldade de dedicar-se a algo que lhe exija algum tipo de compromisso (estudo e/ou trabalho), nem mesmo em atividades que reconhece sentir prazer (relações interpessoais, atividade esportiva, hobby, etc), revelando uma postura desmotivada diante de diferentes contextos. Evidenciava vínculo terapêtico oscilante entre a confiança/abertura e timidez/ introspecção. Frequentemente esquecia os horários agendados, fazendo com que a mãe ligasse solicitando nova consulta. Nos atendimentos, Eduardo demonstrava pouca crítica sobre o uso de álcool e outras drogas, tentando omitir dados da realidade, usando de mentiras para defender-se. Negava as dificuldades enfrentadas em decorrência do uso de substâncias como abstenção e baixo rendimento acadêmico e conflitos familiares. Eduardo referiu fazer uso de cocaína há dois anos, ao que ele chamava de "recreação", referindo-se ao uso com os amigos e em contextos sociais. Inicialmente fazia uso de álcool e maconha tendo, posteriormente, acrescentado a cocaína, sempre aos finais de semana. Gradativamente, as quantidades de bebida e de substâncias foram aumentando em quantidade e frequência de utilização. Relatou que embora trabalhasse com o pai, reconhecia dificuldade de relacionamento com ele. Demonstrava capacidade crítica empobrecida, parecendo expressar a dificuldade de entrar em contato com os reais conflitos vivenciados. $\mathrm{O}$ aprendizado familiar, manifesto a partir das entrevistas, é de que "problemas não devem ser discutidos", não parecendo haver espaço para reflexões, enfrentamento e negociação de conflitos. Somente com muita dificuldade, Eduardo conseguiu apontar a ausência do pai em sua infância e os efeitos que essa condição lhe trouxe. Também, a mágoa que guarda do pai, por este ter vivido uma relação extraconjugal durante cerca de cinco anos o que, segundo ele, o afastou ainda mais do convívio familiar. Eduardo refere a lembrança do comportamento paterno como agressivo, especialmente em relação à mãe, chegando à ocorrência de agressões físicas. Queixa-se da falta de afetividade e atenção do pai que, segundo ele, prefere gritar a conversar, em grande parte do tempo. De modo significativo, Eduardo relatou ressentido uma briga com o pai, por motivo fútil, na qual fora vítima de agressão física. O conteúdo manifesto nas entrevistas iniciais evidenciou dificuldades relacionais familiares enfrentadas por Eduardo, sendo ele o representante de um sistema familiar adoecido.

Após cinco consultas individuais iniciais, a família foi chamada, a fim de que integrasse o tratamento. A mãe mostrou-se receptiva com a nova proposta de tratamento, e embora tenha se mostrado receosa com a possibilidade de participação do marido, o pai compareceu à entrevista seguinte e ambos participaram com envolvimento semelhante. Os pais manifestaram intuito de "ajudar Eduardo", expressando intensa dificuldade de reconhecer os conflitos familiares como participantes, em alguma medida, do sintoma de Eduardo. O filho parece ter "ocupado" os pais, que talvez precisassem de uma estratégia para manter o afastamento conjugal. Nesse sentido, o conflito conjugal aparece voltado para o sintoma do filho, que ocupa o lugar de filho parental. A realização do genograma destacou a dificuldade do exercício da parentalidade de Marcelo e Carla. Ana (10 anos), irmã mais nova de Eduardo, aparece como "figurante" da família, quase inexistente no discurso parental. No momento em que Eduardo demanda a atenção dos pais em função do sintoma da drogadição, Ana fica "abandonada", revelando a dificuldade dos pais de acolher os filhos em suas necessidades. Considerando a questão relacional expressa entre Eduardo e seus pais, parecem expressar o padrão transgeracional de parentalidade já vivenciado por Carla e sua mãe, assim como por Marcelo e seu pai, em que a autoridade parental e o exercício de delimitação de limites cedem lugar à excessiva proximidade e suposta relação de amizade entre pais e filhos. As fronteiras entre o subsistema parental e filial se mostram enfraquecidas, revelando um sistema familiar emaranhado, com papéis familiares confusos e inexpressivos. A dificuldade afetiva no subsistema fraterno revelado pela relação entre Eduardo e Ana parece manter o padrão transgeracional já vivenciado por Carla e sua meia-irmã, que apresentam uma relação de distanciamento afetivo.

Com relação ao vínculo de Eduardo com a mãe, podese referir a proteção e o cuidado expressos em proporção semelhante ao sentimento de invasão de privacidade constante e cobrança extrema. Inicialmente, Eduardo referia uma relação de proximidade com a mãe, situação que foi se modificando com o decorrer dos atendimentos passando a assumir um lugar de "chata e metida" (sic), expressando a fragilidade das fronteiras entre o subsistema parental e filial. O pai de Eduardo pôde mostrar-se mais próximo do filho, condição que deixou Eduardo gratificado e satisfeito. Entretanto, ao melhorar a relação afetiva com o pai, a proximidade com a mãe deu lugar à relação de conflito e distanciamento. É como se melhorando a relação de Eduardo com um dos pais, precise piorar a relação com o outro, já que a família parece não conseguir estabelecer uma relação de proximidade afetiva e gratificante do ponto de vista emocional. A dinâmica familiar parece expressar certa dificuldade de lidar com a proximidade afetiva, sendo preciso um importante conflito para a manutenção da unidade familiar. Assim, o sintoma de Eduardo "congela" o conflito conjugal de seus pais, mantendo o "equilíbrio" familiar, e parece liberar o casal de lidar com a própria conjugalidade, contribuindo para a manutenção da homeostase familiar (Minuchin, 1982). Enquanto os pais voltam-se ao sintoma do filho, não precisam enfrentar a árdua tarefa de lidar com as dificuldades conjugais. 
Em entrevista com a mãe, aspectos do conflito conjugal foram apresentados, revelando a questão do relacionamento extraconjugal do esposo, que é tratada como segredo. Embora de conhecimento dos membros da família, não é um assunto comentado ou discutido na família. O término da relação se deu a partir de uma perseguição de carro em que Carla pediu a companhia do filho para seguir o marido que estava em companhia da amante. $\mathrm{Na}$ ocasião, Carla perdeu o controle do carro, ela e Eduardo sofreram um acidente, tendo sido socorridos pelo pai. Eduardo refere que, a partir deste episódio, houve maior presença do pai na vida familiar. Com isso, sugere-se o exercício de Eduardo como filho parental, que lançaria mão do uso de drogas como forma de lidar com esta situação, parecendo precisar de um grande sintoma para poder diferenciar-se da mãe buscando sua própria identidade (Penso \& Sudbrack, 2004).

A mãe de Eduardo descobriu a reprovação do filho no primeiro semestre da faculdade, por excesso de faltas em todas as disciplinas em curso. Diante disso, a mãe furiosa agrediu fisicamente o filho que permaneceu em silêncio, parecendo expressar o desejo de não estabelecer contato com ninguém, revelando o distanciamento afetivo presente entre os membros da família. O silêncio é, também, uma forma de comunicação, parecendo revelar o distanciamento afetivo que marca a relação familiar. A reprovação de Eduardo na faculdade revelou aos pais o uso contínuo de drogas, evidenciado a gravidade da situação. A partir disso, os pais de Eduardo passaram a depositar na namorada do filho a tarefa de cuidá-lo nas festas e eventos sociais, transferindo à namorada a tarefa parental (Watzlawick, Beavin, \& Jackson, 2007).

O relato do caso revela as dificuldades familiares manifestadas no sintoma da dependência química. O adoecimento de Eduardo expressa a dificuldade do exercício dos papéis parentais, sendo estes delegados à namorada e à psicóloga, representando o serviço de saúde. Os pais manifestam expectativas distintas com relação ao filho, não conseguindo alinhar o discurso parental e o cuidado com afeto e limites, sempre delegando suas decisões e proteção a terceiros. A responsabilidade de Eduardo fazer uso ou não de entorpecentes caberia a então namorada de 15 anos. No curso terapêutico também se observou a repetição do comportamento de Carla, delegando a função de cuidadora ao serviço de saúde mental. A dinâmica familiar é marcada por comunicação incongruente e confusa que, segundo FéresCarneiro (2005), expressam níveis de adoecimento familiar. Duplas mensagens são frequentes, o que se confirma com a família que busca auxílio e se compromete com o tratamento, desde que lhe seja cômodo. Eduardo deveria evitar álcool e manter a medicação, mas para que a família pudesse aproveitar o carnaval lhes era conveniente que a medicação fosse suspensa e que Eduardo pudesse ingerir álcool na companhia dos pais. Com isso, a mensagem parece ser "nos ajude, mas não nos mude!".

Tanto Carla quanto Marcelo expressaram dificuldade acentuada de perceberem como casal parental com dificuldades a serem superadas, tanto em relação ao filho sintomático, quanto à dinâmica familiar estabelecida. Ainda, de verem-se como um casal com importantes conflitos no enfrentamento e resolução conjugalidade.

O pai se fez presente em apenas um atendimento psicológico, oportunidade de grande relevância, já que conteúdos familiares puderam ser tratados no fórum adequado, oportunizando que pais e filho se escutassem e se percebessem como produtores do sintoma vigente. A mãe teve participação constante sistemicamente na produção e manutenção do sintoma do filho. O pai, ainda que tenha participado da entrevista a qual foi chamado, não compareceu mais ao serviço, abandonando a possibilidade de transformação de atendimento individual em atendimento familiar.

Marcelo e Carla demonstraram grande dificuldade em "apropriar-se" do sintoma como expressão de uma dificuldade vivida pela família. Depositar em Eduardo "o problema da família" como único responsável pelas dificuldades enfrentadas parece ter sido menos sofrido do que implicar-se no entendimento de que todos os integrantes da família participam, em alguma medida, da produção do sintoma, assim como da transformação da dinâmica familiar, a fim de buscarem uma melhor qualidade de vida para todos os membros da família.

\section{Considerações finais}

O presente estudo permite suscitar questionamentos e reflexões acerca dos aspectos constitutivos da dinâmica familiar e sua relação com o sintoma das adições. Por óbvio, dado o objetivo desta investigação, não tem a pretensão de fazer generalizações a respeito. Teve tão somente o objetivo de levantar questionamentos acerca da importância da família e seu modo de funcionamento nos contextos de drogadição.

O contexto familiar pode ser considerado como fator de risco e/ou de proteção em relação ao abuso de drogas. Se uma família acolhedora, com limites definidos, comunicação adequada, promotora de afeto e proteção se apresenta como fator de proteção ao uso de drogas; ao contrário, uma família com distanciamento afetivo com dificuldade na comunicação e fronteiras pouco definidas pode favorecer tanto o uso de substâncias como a permanência ativa da dependência. A família apresentada pode ser entendida como fator de risco à drogadição, já que expressa constante presença de duplas mensagens, assim como a falta de nitidez das fronteiras intergeracionais, comunicação inadequada e enfraquecida expressão afetiva. Soma-se a isso a triangulação do filho no conflito conjugal de seus pais.

A partir da teoria familiar sistêmica, compreende-se que o sintoma regula o sistema familiar, mas também denuncia suas dificuldades de enfrentamento das crises específicas ao longo do ciclo vital. Sua função parece ser a de denunciar os engodos familiares como coalizões e alianças. Pode-se inferir que ao drogar-se, Eduardo mantinha a família unida, pois, quando os pais estavam preocupados com seu comportamento adicto, não teriam tempo para lidarem com seus conflitos conjugais. $\mathrm{O}$ uso de drogas colocaria uma cortina de fumaça sobre a situação conflitiva enfrentada por Carla e Marcelo.

$\mathrm{Na}$ família de Eduardo a não funcionalidade e o uso abusivo de drogas são reforçados mutuamente, mantendo, desta forma, a homeostase familiar, que parece sustentar as relações familiares. Para Orth e Moré (2008), famílias em que o dependente químico é do sexo masculino, a figura materna mantém um comportamento superprotetor e permissivo com o dependente, 
definindo o comportamento expresso por Eduardo e sua mãe. $\mathrm{Na}$ família apresentada, a dinâmica familiar se expressa, ainda, com o exercício dos papéis parentais pouco expressivos, disciplina forte e relações afetivas estabelecidas com dificuldade em função do distanciamento afetivo.

A partir do exposto, cabe referir a importância do atendimento psicológico às famílias de dependentes químicos nos serviços públicos de atenção à saúde, serviços que ainda carecem de uma compreensão ampliada do sintoma que é apresentado, não apenas do paciente dependente químico que está adoecido, mas do sistema familiar do qual faz parte. Destaca-se a relevância da família ser acolhida e tratada, visando restaurar os vínculos familiares, estabelecer os limites fragilizados e reorganizar os papéis familiares. A intervenção na família se dá na relação entre os sujeitos envolvidos nos contextos de dependência química, considerando o uso/abuso de substâncias como um fator que, se não é gerado pela organização familiar, parece ser, pelo menos, reforçado por ela, na tentativa de buscar o equilíbrio que ora se perdeu. Nesse sentido, a mudança esperada não se dá apenas no paciente identificado, já que não seria suficiente para evitar a recaída. A partir de uma compreensão sistêmica do sintoma da drogadição, parece necessária uma mudança maior e mais profunda no funcionamento familiar, para sustentar um novo modelo relacional mais funcional e mais saudável, capaz de minimizar a possibilidade de novos sintomas familiares.

Nesta perspectiva, espera-se contribuir de maneira efetiva para suscitar reflexões acerca das relações familiares que se estabelecem nas famílias adictas, bem como das possíveis intervenções, tanto na forma da prevenção quanto na terapêutica dos referidos contextos. Espera-se, ainda, trazer à tona questionamentos significativos no que tange à necessidade de ampliação de investigações, que possam contemplar métodos distintos com maior número de participantes a fim de mapear o fenômeno em diferentes contextos sociais. A partir disso, torna-se possível, quiçá, propor novos modelos de políticas públicas que contemplem a inserção da família nos contextos terapêuticos da dependência química.

\section{Referências}

Achenbach, T., \& Howell, C. (1993). Are American children's problems getting worse? A 13-year comparison. Journal of American Academy on Child and Adolescent Psychiatry, 32, 1145-1154.

Andolfi, M., Ângelo, C., Menghi, P., \& Nicolo-Corigliano, A. (1984). A provocação como intervenção terapêutica. In M. Andolfi, C. Ângelo, P. Menghi \& A. Nicolo-Corigliano (Orgs.), Por trás da máscara familiar: Um novo enfoque em terapia da família (pp. 48-68). Porto Alegre: Artes Médicas.

Beatite, M. (2007). Co-dependência nunca mais (10 $10^{\mathrm{a}}$ ed.). Rio de Janeiro: Record. Brasil, Ministério da Saúde. (2003). A política do Ministério da Saúde para atenção integral a usuários de álcool e outras drogas. Brasília, DF: Autor.

Brasil, V. R. (2004). A recuperação da pessoa do dependente químico: O impacto no seu processo de mudança na família. Família e Comunidade, 1(1), 93-104.

Carvalho, I. M. M. (2001). Brasil: Reestruturação produtiva e condições sociais. Caderno CRH, 35, 123-149. Recuperado de http://www.cadernocrh.ufba. $\mathrm{br} /$ viewarticle.php?id=121

Carvalho, I. M. M., \& Almeida, P. H. (2003). Família e proteção social. São Paulo em Perspectiva, 17(2), 109-122.

Cecconello, A. M., \& Koller, S. H. (2003). Inserção ecológica na comunidade:
Uma proposta metodológica para o estudo de famílias em situação de risco. Psicologia: Reflexão e Crítica, 16(3), 515-524. doi: 10.1590/S010279722003000300010

Copello, A., Velleman, R., \& Tempelton, L. (2005). Family interventions in the treatment of alcohol and drug problems. Drug and Alcohol Review, 24(8), 369-385.

Crepaldi, M. A., \& Wendt, N. C. (2008). A utilização do genograma como instrumento de coleta de dados na pesquisa qualitativa. Psicologia: Reflexão e Crítica, 21(2), 302-310. doi: 10.1590/S0102-79722008000200016

De Leon, G. (2003). A comunidade terapêutica: Teoria, modelo e método ( $2^{\mathrm{a}}$ ed.). São Paulo: Loyola.

De Micheli, D., \& Formigoni, M. L. (2001). As razões para o primeiro uso de drogas e as circunstâncias familiares prevêem os padrões de uso futuro? Jornal Brasileiro de Dependência Química, 2(1), 20-30.

De Micheli, D., Fiesberg, M., \& Formigoni, M. L. (2004). Estudo da efetividade da intervenção breve para o uso de álcool e outras drogas em adolescentes atendidos num serviço de assistência primária à saúde. Revista da Associação Médica Brasileira, 50(3), 305-313.

Féres-Carneiro, T. (2005). Entrevista familiar estruturada (EFE): Um método clínico de avaliação das relações familiares. São Paulo: Casa do Psicólogo.

Fliglie, N., Bordin, S., \& Laranjeira, R. (2010). Aconselhamento em dependência química ( $2^{\underline{a}}$ ed.). São Paulo: Roca.

Fliglie, N., Fontes, A., Moraes, E., \& Payà, R. (2004). Filhos de dependentes químicos com fatores de risco bio-psicossociais necessitam de um olhar especial? Revista de Psiquiatria Clínica, 31(2), 53-62. doi: 10.1590/S010160832004000200001

Gerson, R., \& McGoldrick, M. (2001). Genetogramas e o ciclo de vida familiar. In B. Carter \& M. McGoldrick (Orgs.), As mudanças do ciclo da vida familiar (pp. 144-164). Porto Alegre: Artes Médicas.

Guimarães, F. L., Costa, L. F., \& Lima, M. I. S. (2002). Terapia familiar em contexto de adolescência e drogadição. Inter-Ação: Revista da Faculdade de Educação da UFGO, 27(1), 75-97.

Guimarães, F. L., Costa, L. F., Pessina, L. M., \& Sudbrack, M. F. O. (2009) Famílias, adolescência e drogadição. In L. C. Osório \& M. E. P. Valle (Orgs.), Manual de terapia familiar (pp. 350-365). Porto Alegre: Artmed.

Horta, R. L., Horta, B. L., \& Pinheiro, R. T. (2006). Drogas: Famílias que protegem e que expõem adolescentes ao risco. Jornal Brasileiro de Psiquiatria, 55(4), 268-272. doi: 10.1590/S0047-20852006000400002

Kalina, E. (1999). Drogadição hoje: Indivíduo, família e sociedade. São Paulo: Artes Médicas Sul.

Kalina, E. (2001). Clínica e terapêutica de adicções. Porto Alegre: Artmed.

Landau, J. (2004). O poder em números: O método ARISE para mobilizar família e redes para engajar abusadores de substância no tratamento. Pensando Famílias, 7(6), 11-20.

Laranjeira, R., \& Romano, M. (2004). Consenso brasileiro sobre políticas públicas do álcool. Revista Brasileira de Psiquiatria, 26(Supl. 1), 68-77. doi: 10.1590/ S1516-44462004000500017

Melo, Z. M., Caldas, M. T., Carvalho, M. M. C., \& Lima, A. T. (2005). Família, álcool e violência em uma comunidade da cidade do Recife. Psicologia e Estudo, 10(2), 201-208. doi: 10.1590/S1413-73722005000200006

Minuchin, S. (1982). Famílias: Funcionamento e tratamento. Porto Alegre: Artmed.

Minuchin, S., \& Fishman, C. (1990). Técnicas de terapia familiar. Porto Alegre: Artes Médicas Sul.

Moreira, M. S. S. (2004). Dependência familiar. Revista da SPAGESP - Sociedade de Psicoterapias Analiticas Grupais do Estado de São Paulo, 5(5), 83-88

Nichols, M. P., \& Schwartz, R. C (2007). Terapia familiar-conceitos e métodos. Porto Alegre: Artmed.

Nunõ-Guitièrrez, B. L., \& Gonzalez-Fortaleza, C. (2004). La representación social que orienta las decisiones paternas al afrontar el cosnumo de drogas de sus hijos. Salud Pública de México, 46(2), 123-131. doi: 10.1590/S003636342004000200006 
Orth, A. P. S. (2005). A dependência química e o funcionamento familiar à luz do pensamento sistêmico (Dissertação de Mestrado não publicada). Universidade Federal de Santa Catarina.

Orth, A. P. S., \& Morè, C. L. O. O. (2008). Funcionamento de famílias com membros dependentes de substâncias psicoativas. Psicologia Argumento, 26(55), 293-303

Osório, L. C., \& Valle, M. E. P (Orgs.). (2009). Manual de terapia familiar (Vol. 1). Porto Alegre: Artmed.

Payà, R. (2011). Terapia familiar. In A. Diehl, D. Cordeiro \& R. Laranjeira (Orgs.). Dependência química: Prevenção, tratamento e políticas públicas (319-326). Porto Alegre: Artmed.

Penso, M. A. (2003). Dinâmicas familiares e construções identitárias de adolescentes envolvidos em atos infracionais e com drogas (Tese de Doutorado não publicada). Universidade de Brasília.

Penso, M. A., \& Sudbrack, M. F. (2004). Envolvimento com atos infracionais e com drogas como possibilidades para lidar com o filho parental. Psicologia USP, 15(3), 29-54. doi: 10.1590/S0103-65642004000200003

Raupp, L. M., \& Milnitisky-Sapiro, C. (2008). A "reeducação" de adolescentes em uma comunidade terapêutica: O tratamento da drogadição em uma instituição religiosa. Psicologia: Teoria e Pesquisa, 24(3), 361-368. doi: 10.1590/S0102-37722008000300013

Rodrigues, V. S., Horta, R. L., Costa, L. G., Macedo, R., \& Strey, M. (2008).
Construção de consensos: Paradigma sistêmico e modelo cognitivocomportamental em transtornos por uso de substâncias psicoativas. In R. M. S. Macedo (Org.), Terapia familiar no Brasil e na última década (pp. 72-78). São Paulo: Roca.

Schenker, M., \& Minayo, M. C. S. (2003). A implicação da família no uso abusivo de drogas: Uma revisão crítica. Ciência \& Saúde Coletiva, 8(1), 299-306. doi: 10.1590/S1413-81232003000100022

Schenker, M., \& Minayo, M. C. S. (2004). A importância da família no tratamento do uso abusivo de drogas: Uma revisão da literatura. Cadernos de Saúde Pública, 20(3), 649-659. doi: 0.1590/S0102-311X2004000300002

Seadi, S. S., \& Oliveira, M. S. (2009). A terapia multifamiliar no tratamento da dependência química: Um estudo retrospectivo de seis anos. Psicologia Clínica, 21(2), 363-378.

Silva, E. A. (2001). Abordagens familiares. Jornal Brasileiro de Dependência Química, 2(Supl. 1), 21-24. doi: 10.1590/S0103-56652009000200008

Sudbrack, M. F. O. (2001). Terapia familiar sistêmica. In S. D. Seibel \& A. Toscano Junior (Orgs.), Dependência de drogas (pp. 403-415). São Paulo: Atheneu.

Watzlawick, P., Beavin, J. H., \& Jackson, D. (2007). Pragmática da comunicação humana. São Paulo: Cultrix.

Zeni, T. C., \& Araujo, R. B. (2011). Relação entre craving por tabaco e o craving por crack em pacientes internados para desintoxicação. Jornal Brasileiro de Psiquiatria, 60(1), 28-33. doi: 10.1590/S0047-20852011000100006

Fernanda Marques Paz, especialização em Psicoterapia Familiar e de Casal (Unisinos), especialização em Prevenção e Abordagem em Dependência Química (FACOS), é Psicóloga no Centro de Atenção Psicossocial (CAPS) Casa Aberta. Endereço para correspondência: Santos Dumont, 92, Centro, Osório-RS, CEP 95520000. Tel: (51) 8136-4822. Email: Fepaz84@yahoo.com.br

Patrícia Manozzo Colossi, Mestre em Psicologia Clínica (Unisinos); doutoranda em Psicologia Clínica (Unisinos); Especialista em Psicoterapia de Casais e Famílias (Unisinos), professora e supervisora da graduação em Psicologia-Faculdades Integradas de Taquara-FACCAT, supervisora do Centro de Serviços em Psicologia-CESEP/FACCAT

Psicóloga Clínica de Adultos, Casais e Famílias. Email: pmcolossi@gmail.com 